\title{
Characteristics of Phytase Enzyme and its Role in Animal Nutrition
}

\author{
Geetha Shanmugam* \\ Department of Plant Biotechnology, Centre for plant Molecular Biology and Biotechnology, \\ Tamil Nadu Agricultural University, Coimbatore-641003 (Tamil Nadu), India \\ *Corresponding author
}

\begin{tabular}{|c|c|}
\hline & A B S T R A C T \\
\hline $\begin{array}{l}\text { Phytase, Phytate, } \\
\text { phosphorus, } \\
\text { Hydrolysis, } \\
\text { Nutrition }\end{array}$ & \multirow{3}{*}{$\begin{array}{l}\text { Cereals, legumes and oilseed crops are grown over } 90 \% \text { of the world's harvested area. Together } \\
\text { they serve as a major source of nutrients for the animal kingdom. An important constituent of } \\
\text { seeds of these crops is phytic acid (myo-inositol } 1,2,3,4,5,6 \text {-hexakisphosphate; Ins } \mathrm{P}_{6} \text { ). The } \\
\text { salt form, phytate, is an anhydrous storage form of phosphate accounting for more than } 80 \% \text { of } \\
\text { the total phosphorus in cereals and legumes. In contrast to other organo-phosphate molecules, } \\
\text { phytate contains a high phosphate content, which results in a high negative charge over a wide } \\
\text { pH range. Under normal physiological conditions phytic acid chelates essential minerals such } \\
\text { as calcium, magnesium, iron and zinc. Phytic acid also binds to amino acids and proteins and } \\
\text { inhibits digestive enzymes. Thus, phytic acid is an anti-nutritive component in plant-derived } \\
\text { food and feed, and therefore, the enzymatic hydrolysis of phytic acid is desirable. The enzyme } \\
\text { phytase is able to release the bioavailable phosphorus from phytic acid, consequently } \\
\text { improving the phosphorus bioavailability and uptake of minerals. }\end{array}$} \\
\hline Article Info & \\
\hline $\begin{array}{l}\text { Accepted: } \\
\text { 10 February } 2018 \\
\text { Available Online: } \\
10 \text { March } 2018\end{array}$ & \\
\hline
\end{tabular}

\section{Introduction}

Phosphorus is one of the most limiting nutrients for animals because most of the phosphorus in the plant seeds including the feeding plants is in the form of phytic acid, most of which cannot be digested by monogastric animals and acts as an antinutritional factor hindering the uptake of a range of minerals. In the current poultry industry, phytase is commonly added to poultry diets to improve $\mathrm{P}$ utilization, which leads to a decrease in feed cost and $P$ excretion in the environment (Dersjant et al., 2015). A better understanding of in vivo phytase activity is important so as to use phytase more economically and efficiently.

\section{myo-Inositol hexakisphosphate}

myo-inositol hexakisphosphate is the most abundant phosphorylated derivative of myoinositol found in nature and has been more commonly referred to as phytic acid (Figure 1). Phytic acid is chemically described as myoinositol 1, 2, 3, 4, 5, 6-hexakis dihydrogen phosphate or Ins $\mathrm{P}_{6}$ (IUPAC-IUBMB, 1992).

\section{Occurrence and Distribution}

The seeds of cereal grains and legumes show the highest content of phytate among plants (Reddy et al., 1989). Ins $\mathrm{P}_{6}$ has also been found in pollen, spores (DeMaggio and Stetler, 1985), and vegetative tissues, such as 
roots, stems and leaves (Campbell et al., 1991). Until recently, Ins $P_{6}$ was thought to be restricted to plants, but later studies have revealed that higher inositol polyphosphates are widespread and perhaps ubiquitous among eukaryotes (Sasakawa et al., 1995). Nonruminants are unable to metabolize phytate, making a majority of phosphorus in seed unavailable to these animals. The addition of phytase to the diet of monogastric livestock has been examined as a way to reduce phosphorus pollution resulting from intensive livestock operations (Reddy et al., 1989).

\section{Phytic acid hydrolysis}

The principle end products of phytase action are phosphoric acid and myo-inositol, but the phosphatidylinositols representing various degrees of dephosphorylation from inositol hexakisphosphate to inositol are generated as intermediates, or in some cases, as end products (Figure 2) (Wodzinski and Ullah, 1996).

Phytate also chelates trace elements of iron and zinc between phosphate groups within a single phytate molecule or between two phytate molecules. Phytase is the only known enzyme that can initiate the phosphate hydrolysis at carbon 1,3 or 6 in the inositol ring of phytate. The removal of phosphate group by phytase results in releasing of calcium, iron, zinc, and other metals. Most characterized phytases hydrolyze Ins $\mathrm{P}_{6}$ in a stepwise manner, yielding myo-inositol pentakis-, tetrakis-, tris-, bis- and monophosphate products (Konietzny and Greiner, 2002).

\section{Phytase}

Phytases are a special class of phosphatases that catalyze the sequential hydrolysis of myoinositol-(1, 2, 3, 4, 5, 6)-hexakisphosphate or phytic acid (Ins $\mathrm{P}_{6}$ ) to less phosphorylated myo-inositol derivatives and inorganic phosphate. Phytate degrading activity has been detected in plants, microorganisms, and in some animal tissues and phytases from several plant and microbial species (Haros et al., 2007) have been purified and characterized. Hence, although currently phytases are used mainly as animal feed additives in diets of monogastric animals, there is a great potential for the use of this class of enzymes in processing and manufacturing of food for human consumption (Jorquera et al., 2008). The International Union of Biochemistry (1979) recognizes two general classes of phytases, 3-phytase and 6-phytase based on the location of the phosphate group, within the phytin molecule, that is hydrolyzed first. Microbial or fungal phytases typically hydrolyze the phosphate at the three position and plant phytase at the six position of the phytin molecule. After releasing the first phosphate group, the five remaining phosphate groups can be sequentially released from phytin by phytase which is present in large quantities in the digestive tract (Maenz and Classen, 1998).

\section{Sources of phytases}

\section{Microbial sources}

Phytate degrading enzymes have been most commonly found in fungi, particularly from the Aspergillus species (Konietzny and Greiner, 2002). The phytase from A. ficuum was the first studied for use as a commercial product. Phytate degrading enzymes have also commonly been found in many bacteria.

\section{Plant sources}

Phytase activity has been found in many plants, such as maize (Laboure et al., 1993), barley, rye (Greiner et al., 2000), spelt (Konietzny et al., 1995), canola seed (Houde et al., 1990) and lily pollen (Scott, 1991). 


\section{Animal sources}

Phytate-degrading enzymes have been isolated from the intestinal mucosae of some monogastric animals (Chi et al., 1999). A multiple inositol polyphosphate phosphatase (MIPP) displaying phytate degrading activity was also identified in rat hepatic tissue, localized in the ER lumen. A phytatedegrading enzyme has also been purified and characterized from the protozoan Paramecium (Freund et al., 1992).

\section{The physiological nature of phytate}

Phytate can exist in a metal-free form or in metal-phytate complex, depending on the $\mathrm{pH}$ of the solution and the concentration of metal cations. At acidic $\mathrm{pH}$, protonation of the phosphate groups of phytate generates the metal-free form. At neutral $\mathrm{pH}$, in contrast, deprotonation of the phosphate groups of phytate enhances the affinity for divalent metal cations and thus phytate forms metalphytate complexes with divalent metal cations, mostly $\mathrm{Mg}^{2+}$ and $\mathrm{Ca}^{2+}$ (Maenz et al., 1999). During the germination of seed, phytate is degraded by phytases, providing phosphate and minerals for the growing seedlings. In addition to its role in phosphate storage, phytate acts as a strong chelator for divalent metal cations and exists as a stable metalphytate complex with divalent metal cations (mostly $\mathrm{K}^{+}, \mathrm{Mg}^{2+}, \mathrm{Ca}^{2+}$, or $\mathrm{Zn}^{2+}$ ) in plants (Reddy et al., 1989).

\section{Storage of phytic acid}

Phytic acid and its co-precipitated cations are stored in electron dense spherical particles named globoids. The globoids are localised predominantly in the aleurone layer (wheat and barley) or in the embryo (maize) (O'Dell et al., 1972). They are compartmentalised inside protein storage vacuoles in the seeds. The phosphorus fraction stored as phytate range from $30 \%$ in roots up to $80 \%$ in seeds and cereals. The highest amount of phytate among cereals is found in maize (0.83-2.22\%) and among legumes in dolique beans (5.929.15\%) (Reddy et al., 1989).

\section{Dephytinisation and nutrition}

The chelating properties of PA not only result in the binding of cations in seeds. Iron and zinc uptake have both been shown to be inhibited when the phytic acid: metal ratio increases above 10:1 (Gharib et al., 2006). Milling of cereals removes the phytic acid, but this treatment also removes the major parts of the minerals and dietary fibres and cannot therefore be a nutritional solution to the problem. Similarly, soaking or extracting in aqueous solutions can remove up to two thirds of the PA by the action of endogenous phytase activity, but loss of minerals, waterextractable proteins and vitamins also occurs (Hurrell, 2004).

Avoiding PA formation in the first place or catalysing its degradation by the use of PA hydrolysing enzymes would therefore be more beneficial approaches to dephytinisation. Reducing phytate content through lpa mutants have been attempted through knock-out of genes involved in PA biosynthesis. Furthermore, the yield or germination ability is affected if PA content is reduced more than $50 \%$, thereby making this approach unattractive from an economic perspective.

Instead of blocking its biosynthesis, an attempt to reduce PA in wheat products has been performed by introducing the Aspergillus niger phytase gene phyA into a wheat variety by particle bombardments of immature wheat embryos (Holm et al., 2002). Wheat, barley and rye all have high phytase activity in the grain, whereas maize, millet and sorghum have low initial phytase activity that increase rapidly after germination (Egli et al., 2002). 
Fig.1 Chemical structure of phytic acid

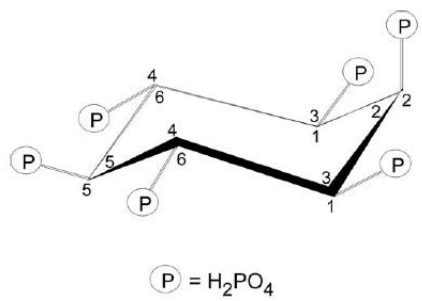

Fig.2 Phytate hydrolysis

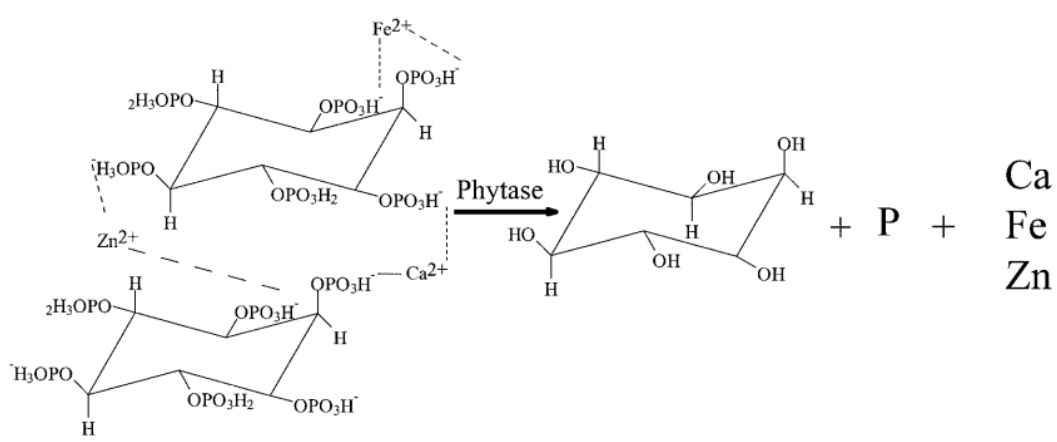

\section{The biochemical properties of phytases}

Most phytases belong to either the acid phytases or the alkaline phytases, depending on their optimal $\mathrm{pH}$ for catalytic activity. Histidine acid phosphatases (HAPs) from $E$. coli, K. terrigena (Greiner et al., 1997), Aspergillus niger, Aspergillus fumigatus (Ullah et al., 2000), canola seeds (Houde et al., 1990), and spelt (Konietzny et al., 1995) have an optimal $\mathrm{pH}$ range of 4.5-5.5. In contrast, alkaline phytases from Bacillus (Idriss et al., 2002) and some plant seeds, such as Typha latifolia L. pollen and Lilium longiflorum pollen (Scott, 1991), have an optimal $\mathrm{pH}$ range of 6.5-8.0. All phytases are monomeric proteins, except for phytase $\mathrm{B}$ from A. niger, which is a tetramer. The molecular masses of the enzymes are quite variable, within the range $38-100 \mathrm{kDa}$. Most phytases have an optimal temperature of 44$60^{\circ} \mathrm{C}$. In contrast, phytases from Aspergillus fumigatus and Bacillus amyloliquefaciens have an optimum temperature of about $70^{\circ} \mathrm{C}$. To use phytases as animal feed additives, thermostability of the enzyme is a highly desirable property during the animal feedpelleting process $\left(80-100^{\circ} \mathrm{C}\right)$. Alkaline phytases from Bacillus are quite stable at the high temperature range of $80-95^{\circ} \mathrm{C}$, while other phytases are rapidly inactivated above $60^{\circ} \mathrm{C}$ (Tomschy et al., 2002). The phytase from Bacillus amyloliquefaciens is an extremely thermostable enzyme, based on Tm values $\left(80^{\circ} \mathrm{C}\right.$, the denaturation temperature) determined by differential scanning calorimetry (Ha et al., 2000).

\section{Molecular and biophysical characteristics of phytases}

They are classified according to their $\mathrm{pH}$ optimum as acid or alkaline phytases, according to the position of their initial hydrolysis of phytate as 3-phytases, 6phytases or 5-phytases, and according to their catalytic mechanisms as belonging to the histidine acid phosphatases (HAPs), purple acid phosphatases (PAPs), cysteine phosphatases (CPs) or $\beta$-propeller phytases 
(BPPhys) (Lei et al., 2007). One of the major classes is the family of HAPs sharing a highly conserved RHGXRXP motif (Van Etten et al., 1991). The HAP class can be further subdivided into three 368 different groups (PhyA-PhyC), based on amino acid sequence homology and biochemical properties, such as optimal $\mathrm{pH}$ and the position-specificity of phytate hydrolysis. Group I, PhyA, consists of enzymes with 465-469 amino acids and includes extracellular HAPs from Aspergillus niger, Aspergillus niger (awamori) (Piddington et al., 1993), Aspergillus fumigatus, Aspergillus terrus, Emericella nidulans, Talaromyces thermophilus (Pasamontes et al., 1997). These phytases have two optimal $\mathrm{pH}$ values $(2.5,5.5)$ and an optimal temperature at $55-60^{\circ} \mathrm{C}$ (Wyss et al., 1999). The molecular mass of the unglycosylated phytases is predicted to be 48-50 kDa.

Group II, PhyB, contains phytases that are extracellular HAPs from Aspergillus niger (Ethrlich et al., 1993), Saccharomyces cerevisiae and Shizosaccharomyces pombe (Elliott et al., 1986). They are composed of 453-479 amino acids and the molecular mass is $\sim 48-50 \mathrm{kDa}$. The apparent molecular mass of the glycosylated proteins is $65 \mathrm{kDa}$ by SDS-PAGE and about $270 \mathrm{kDa}$ by analytical centrifugation (Kostrewa et al., 1999). These phytases have a single optimal $\mathrm{pH}$ of 2.5 , lack any activity at $\mathrm{pH} 5.0$ or higher, and have an optimal temperature of $55-60^{\circ} \mathrm{C}$. PhyB hydrolyzes the same position of metal-free phytates and is classified as a 3-phytase.

Group III, PhyC, contains acid phytases from E. coli (Dossa et al., 1990), lysosomal (Geier et al., 1991), and prostatic acid phosphatases (Van Etten et al., 1991) from rat and human. These phytases are intracellular proteins composed of 354-439 amino acids, with a molecular mass of $\sim 42-45 \mathrm{kDa}$; and these monomeric proteins are nonglycosylated enzymes. PhyC have a single optimal $\mathrm{pH}$ ( 5.0-6.0) and exhibit an optimal temperature at $40-60^{\circ} \mathrm{C}$. Group III phytases are also capable of hydrolyzing not only metal free phytate but also various other phosphate esters, like other HAPs (Wyss et al., 1999). However, these phytases are considered as a 6-phytase, since they hydrolyze phytate preferentially at the D-6 (1-4) position (Lei et al., 2013).

Another major class (Class II) contains alkaline phytases, which differ from HAPs in many aspects, including optimal $\mathrm{pH}$, molecular mass, tertiary structure, substrate specificity, and calcium ion requirement for enzymatic catalysis. Based on these biochemical differences and phylogenetic data, alkaline phytases from Bacillus and some plant seeds can be classified as another group: PhyD. Group IV, PhyD, consists of the phytate-specific enzymes from Bacillus and some plants, such as T. lattifolia pollen (Hara et al., 1985), L. longiflorum pollen (Barrientos et al., 1994), and some legume seeds (Scott, 1991). Comparison of amino acid sequences among these enzymes is impossible, since no amino acid sequence data is available for the plant alkaline phytases. However, these plant enzymes have biochemical characteristics very similar to those of the phytases from Bacillus (Oh et al., 2001). They are composed of 383 amino acids and encode an extracellular monomeric protein. The molecular mass is $\sim 42 \mathrm{kDa}$; and SDS-PAGE gives an apparent molecular mass of $~ 38-44 \mathrm{kDa}$. A phytase that works over a wide range of $\mathrm{pH}$ and is active up to the stomach and upper intestine would be the ideal phytase for animal feed (Dersjant et al., 2015).

\section{Crystal structure}

The crystal structure of the A. niger and $E$. coli enzyme closely resembles the overall fold 
of other histidine acid phosphatases. These structures contain a conserved $\alpha / \beta$-domain and a variable $\alpha$-domain. The active site is located at the interface between the two domains. Differences in substrate binding have been attributed to differences in the $\alpha$ domain. The proposed structures also provide information about substrate binding and the catalytic mechanism on the molecular level (Lim et al., 2000).

The ruminants digest phytic acid through the action of phytases produced by the anaerobic gut fungi and bacteria present in their rumenal microflora. However, monogastric animals such as pig, poultry and fish utilize phytate phosphorus poorly because they are deficient in gastrointestinal tract phytases. Therefore, supplemental inorganic phosphate is added to their feed to meet the phosphate requirement and to ensure good growth. However, supplemental inorganic phosphate does not diminish the anti-nutritive effect of phytic acid. Therefore, phytase has become an important industrial enzyme and is the object of extensive research. By working efficiently on the substrate in the prevailing conditions, supplemental phytase could diminish the antinutritive effects of phytic acid and reduce the cost of diets by removing or reducing the need for supplemental inorganic phosphate.

In addition, phytase would be an environmentally friendly product, reducing the amount of phosphorus entering the environment. Recently, was conducted to determine the effect of superdosing phytase on productive performance and egg quality in laying hens (Jong Hyuk Kim et al., 2017). Hence, Nutritional genomics is expected to improve efficiency of $\mathrm{P}$ utilization in livestock (Kebreab et al., 2012). Approaches to problems represented by seed phytic acid include engineering crops to express high levels of phytase enzyme in seeds (Raboy et al., 2000), or breeding crops with reduced levels of seed phytic acid (low-phytate or high-available P (Cichy and Raboy, 2008).

\section{References}

Barrientos, L., J.J. Scott and P.P. Murthy. 1994. Specificity of hydrolysis of phytic acid by alkaline phytase from lily pollen. Plant Physiol., 106: 1489-1495.

Campbell, M., R. Dunn, R. Ditterline, S. Pickett and V. Raboy. 1991. Phytic acid represents 10 to $15-$ percent of total phosphorus in alfalfa root and crown. J. Plant Nutr., 14: 925-937.

Chi, H.B., G.E. Tiller, M.J. Dasouki, P.R. Romano, J. Wang, R.J. O'Keefe, J.E. Puzas, R.N. Rosier and P.R. Reynolds. 1999. Multiple inositol polyphosphate phosphatase: Evolution as a distinct group within the histidine phosphatase family and chromosomal localization of the human and mouse genes to chromosomes 10q23 and 19. Genomics, 56: 324-336.

Cichy, K.A. and V. Raboy. 2008. Evaluation and development of low phytate crops, In: $\mathrm{H}$. Krishnan (Ed.), Modification of Seed Composition to Promote Health and Nutrition, Agronomy Monograph 51, American Society of Agronomy and Crop Science Society of America, pp. 177-200.

DeMaggio, A.E and D.A. Stetler. 1985. Mobilisation of storage reserves during fern spore germination. Proc. R. Soc. Edinb., 86: 195202.

Dersjant-Li, Y., A, Awati, H, Schulze and G, Partridge. 2015. Phytase in non-ruminant animal nutrition: a critical review on phytase activities in the gastrointestinal tract and influencing factors. J Sci Food Agric., 95: $878-96$.

Dossa, J., C. Marck and P.L. Boquet. 1990. The complete nucleotide sequence of the Escherichia coli gene appA reveals significant homology between $\mathrm{pH} 2.5$ acid phosphtase and glucose-1- phosphatase. J. Bacteriol., 172: 5497-5500.

Egli, I., L. Davidsson, M.A. Juillerat, D. Barclay and R.F. Hurrell. 2002. The influence of soaking and germination on the phytase activity and phytic acid content of grains and seeds potentially useful for complementary feeding. J. Food Sci., 67: 3484-3488.

Elliott, S., C.W. Chang, M.E. Schweingruber, J. Schaller, E.E. Rickli and J. Carbon. 1986. 
Isolation and characterization of the structural gene for secreted acid phosphatase from Schizosaccharomyces pombe. J. Biol. Chem., 261: 2936-2941.

Ethrlich, K.C., B.G. Montalbano, E.J. Mullaney, H.C. Dischinger and A.H.J. Ullah. 1993. Identification and cloning of a second phytase gene (phyB) from Aspergillus niger (ficcum). Biochem. Biophys. Res. Commun., 195: 5357.

Freund, W.D., G.W. Mayr, C. Tietz and J.E. Schultz. 1992. Metabolism of inositol phosphates in the protozoan Paramecium - characterization of a novel inositol-hexakisphosphatedephosphorylating enzyme. Eur. J. Biochem., 207: 359-367.

Geier, C., K. Von Figura and R. Pohlmann. 1991. Molecular cloning of the mouse lysosomal acid phosphatase. Biol. Chem. Hoppe Seyler., 372: 301-304.

Gharib, A.G., S.G. Mohseni, M. Mohajer and M. Gharib. 2006. Bioavailability of essential trace elements in the presence of phytate, fiber and calcium. J. Radioanalytical Nuclear Chem., 270: 209-215.

Greiner, R., E. Haller, U. Konietzny and K.D. Jany. 1997. Purification and characterization of a phytase from Klebsiella terrigena. Arch. Biochem. Biophys., 341: 201-206.

Greiner, R., K.D. Jany and M.L. Alminger. 2000. Identification and properties of myo-inositol hexakisphosphate phosphohydrolases (phytases) from barley (Hordeum vulgare). J. Cer. Sci., 31: 127-139.

Ha, N.C., B.C. Oh, S. Shin, H.J. Kim, T.K. Oh, Y.O. Kim, K.Y. Choi and B.H. Oh. 2000. Crystal structures of a novel, thermostable phytase in partially and fully calcium-loaded states. Nat. Struct. Biol., 7: 147-153.

Haros, M., M. Bielecka, J. Honke and Y.Sanz. 2007. Myo-inositol hexakisphosphate degradation by Bifidobacterium infantis ATCC 15697. Inter. J. Food Microbiol., 117: 76-84.

Holm, P.B., K.N. Kristiansen and H.B. Pedersen. 2002. Transgenic approaches in commonly consumed cereals to improve iron and zinc content and bioavailability. J. Nutri., 132: 514-516.

Houde, R.L., I. Alli and S. Kermasha. 1990. Purification and characterization of canola seed (Brassica sp) phytase. J. Food Biochem., 14: 331-351.
Hurrell, R.F. 2004. Phytic acid degradation as a means of improving iron absorption. Int. J. Vitam. Nutr. Res., 74: 445-452.

Idriss, E.E., O. Makarewicz, A. Farouk, K. Rosner, R. Greiner, H. Bochow, T. Richter and R. Borriss. 2002. Extracellular phytase activity of Bacillus amyloliquefaciens FZB45 contributes to its plant growth-promoting effect. Microbiology, 148: 2097-2109.

International Union of Biochemistry. 1979. In: Enzyme Nomenclature: Recommendations of the Nomenclature Committee of the International Union of Biochemistry. Academic Press, New York, NY. pp. 242-247.

Jong Hyuk Kim, Franco Martinez Pitargue, Hyunjung Jung, Gi Ppeum Han, Hyeon Seok Choi and Dong Yong Kil. 2017. Effect of superdosing phytase on productive performance and egg quality in laying hens., Asian-Australas J Anim Sci., 30(7): 994-998.

Jorquera, M., O. Martinez, F. Maruyama, P. Marschiner and M.D.L.L. Mora. 2008. Current and future biotechnology applications of bacterial phytases and phytase-producing bacteria. Microbes Environ., 23: 182-191.

Kebreab, K., A.V. Hansen., A.B. Strathe. 2012. Animal production for efficient phosphate utilisation: from optimized feed to high efficiency livestock. Curr. Opi. Biotechnol., 23: 872-877.

Konietzny, U. and R. Greiner. 2002. Molecular and catalytic properties of phytate-degrading enzymes (phytases). Int. J. Food Sci. Technol., 37: 791-812.

Konietzny, U., R. Greiner and K.D. Jany. 1995. Purification and characterisation of a phytase from spelt. J. Food Biochem., 18: 165-183.

Kostrewa, D., M. Wyss, A. D'Arcy and A.P. van Loon. 1999. Crystal structure of Aspergillus niger $\mathrm{pH} 2.5$ acid phosphatase at $2.4 \AA$ resolution. J. Mol. Biol., 288: 965-974.

Laboure, A.M., J. Gagnon and A.M. Lescure. 1993. Purification and characterization of a phytase (myo-inositol- hexakisphosphate phosphohydrolase) accumulated in maize (Zea mays) seedlings during germination. Biochem. J., 295: 413-419.

Lei, X.G., J.D. Weaver, E. Mullaney., A.H. Ullah and M.J. Azain., 2013. Phytase, a new life for an 'old' enzyme. Annu Rev Anim Biosci., 1:283309. 
Lei, X.G., J.M. Porres, E.J. Mullaney and H. BrinchPedersen. 2007. Phytase: source, structure, and application. In: Industrial Enzymes: Structure, Function and Applications (Polaina, J. and Maccabe, A.P., eds). New York: Springer, Dordrecht, The Netherlands, pp. 505-529.

Lim, D., S. Golovan, C.W. Forsberg and Z. Jia. 2000. Crystal structures of Escherichia coli phytase and its complex with phytate. Nat. Struct. Biol., 7: 108-113.

Maenz, D.D. and H.L. Classen. 1998. Phytase activity in the small intestinal brush border membrane of the chicken. Poult. Sci., 77: 557563.

O'Dell, B.L., A.R. de Boland and S.R. Koirtyohann. 1972. Distribution of phytate and nutritionally important elements among the morphological components of cereal grains. J. Agric. Food Chem., 20: 718-721.

Oh, B.C., B.S. Chang, K.H. Park, N.C. Ha, H.K. Kim, B.H. Oh and T.K. Oh. 2001. Calciumdependent catalytic activity of a novel phytase from Bacillus amyloliquefaciens DS11. Biochemistry, 40: 9669-9676.

Pasamontes, L., M. Haiker, M. Henriquez-Huecas, D.B. Mitchell and A.P.G.M. van Loon. 1997a. Cloning of the phytases from Emericella nidulans and the thermophilic fungus Talaromyces thermophilus. Biochim. Biophys. Acta., 1353: 217-223.

Piddington, C.S., C.S. Houston, M. Paloheimo, M. Cantrell, A. Miettinen-Oinonen, H. Nevalainen and J. Rambosek. 1993. The cloning and sequencing of the genes encoding phytase (phy) and $\mathrm{pH}$ 2.5- optimum acid phosphatase (aph) from Aspergillus niger var. awamori. Gene, 133: 55-62.

Raboy, V., P. Gerbasi, K.A. Young, S. Stoneberg, S.G. Pickett, A.T. Bauman, P.P.N. Murthy, W.F. Sheridan, D.S. Ertl. 2000. Origin and seed phenotype of maize low phytic acid 1-1 and low phytic acid 2-1, Plant Physiol., 124: 355-368.
Reddy, N.R., M.D. Pierson, S.K. Sathe and D.K. Salunkhe. 1989. Phytates in cereals and legumes. Boca Raton, CRC Press, Inc. pp.155.

Sasakawa, N., M. Sharif and M.R. Hanley. 1995. Metabolism and biological-activities of inositol pentakisphosphate and inositol hexakisphosphate. Biochem. Pharmacol., 50: 137-146.

Scott, J.J. 1991. Alkaline phytase activity in nonionic detergent extracts of legume seeds. Plant Physiol., 95: 1298-1301.

Tomschy, A., R. Brugger, M. Lehmann, A. Svendsen, K. Vogel, D. Kostrewa, S.F. Lassen, D. Burger, A. Kronenberger, A.P. van Loon, L. Pasamontes and M. Wyss. 2002. Engineering of phytase for improved activity at low $\mathrm{pH}$. Appl. Environ. Microbiol., 68: 1907-1913.

Ullah, A.H., K. Sethumadhavan, X.G. Lei and E.J. Mullaney. 2000. Biochemical characterization of cloned Aspergillus fumigatus phytase (phyA). Biochem. Biophys. Res. Commun., 275: 279-285.

Van Etten, R.L., R. Davidson, P.E. Stevis, H. MacArthur and D.L. Moore. 1991. Covalent structure, disulfide bonding, and identification of reactive surface and active site residues of human prostatic acid phosphatase. J. Biol. Chem., 266: 2313-2319.

Wyss, M., L. Pasamontes, A. Friedlein, R. Remy, M. Tessier, A. Kronenberger, A. Middendorf, M. Lehmann, L. Schnoebelen, U. Rothlisberger, E. Kusznir, G. Wahl, F. Muller, H.W. Lahm, K. Vogel and A.P. van Loon. 1999. Biophysical characterization of fungal phytases (myo-inositol hexakisphosphate phosphohydrolases): molecular size, glycosylation pattern, and engineering of proteolytic resistance. Appl. Environ. Microbiol., 65: 359-366.

\section{How to cite this article:}

Geetha Shanmugam. 2018. Characteristics of Phytase Enzyme and Its Role in Animal Nutrition. Int.J.Curr.Microbiol.App.Sci. 7(03): 1006-1013. doi: https://doi.org/10.20546/ijcmas.2018.703.120 